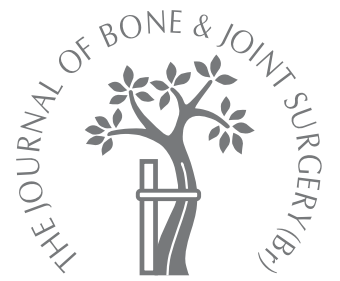

C. Bochang,

Y. Jie,

W. Zhigang,

D. Weigl,

E. Bar-On,

K. Katz

From the Shanghai

Children's Medical

Center, Shanghai 2 nd

Medical University,

Shanghai, China and

Schneider Children's

Medical Center of

Israel, Petah Tiqwa

and Sackler Faculty

of Medicine, Tel Aviv

University, Tel Aviv,

Israel

C. Bochang, MD, Physician

in Chief, Professor of

Orthopaedic Surgery

W. Zhigang, MD,

Orthopaedic Surgeon

Y. Jie, MD, Orthopaedic

Surgeon

Department of Paediatric

Orthopaedic Surgery

Shanghai Children's Medical

Center, 1678 Dongfang Road,

Shanghai 200127, China.

D. Weigl, MD, Orthopaedic

Surgeon

E. Bar-On, MD

Orthopaedic Surgeon,

Lecturer

K. Katz, MD, Associate

Professor of Orthopaedic

Surgery

Orthopaedic Unit

Schneider Children's Medica

Center of Israel, 14 Kaplan

Street, Petah Tiqwa 49202,

Israel.

Correspondence should be sent to Professor K. Katz; e-mail: katzzz@bezeqint.net

C2005 British Editorial Society of Bone and Joint Surgery

doi:10.1302/0301-620X.87B7. $15774 \$ 2.00$

$J$ Bone Joint Surg [Br] 2005;87-B:994-6.

Received 28 June 2004;

Accepted 12 January 2005

\title{
Immobilisation of forearm fractures in children
}

\author{
EXTENDED VERSUS FLEXED ELBOW
}

\begin{abstract}
Redisplacement of unstable forearm fractures in plaster is common and may be the result of a number of factors. Little attention has been paid to the influence of immobilisation with the elbow extended versus flexed. We prospectively treated 111 consecutive children from two centres with closed forearm fractures by closed reduction and casting with the elbow either extended (60) in China or flexed (51) in Israel. We compared the outcome of the two groups. There was no statistically significant difference in the distribution of the age of the patients, the site of fracture or the amount of angulation and displacement between the groups. During the first two weeks after reduction, redisplacement occurred in no child immobilised with the elbow extended and nine of 51 children (17.6\%) immobilised with the elbow flexed. Immobilisation of unstable forearm fractures with the elbow extended appears to be a safe and effective method of maintaining reduction.
\end{abstract}

Fracture of a forearm bone is the most common type of fracture in children. Displaced or angulated fractures frequently require reduction and immobilisation in an above-elbow plaster cast. Redisplacement is common and may result from a number of factors. ${ }^{1-3}$

Little attention has been paid to the effect on fracture stability after closed reduction of immobilisation with the elbow flexed or extended. ${ }^{4-6}$ Recommendations for immobilisation have been based on theory, experience and tradition. ${ }^{1}$ This prospective study was designed to compare the outcome of forearm fractures immobilised with the elbow extended or flexed.

\section{Patients and Methods}

Between March 2002 and May 2003, we studied 111 children with closed fractures of the radius, ulna or both who underwent closed reduction in two centres. We excluded children with open fractures, fracture-dislocations, and growth plate fractures.

The patients were divided into two groups. We treated 60 consecutive children (44 boys and 16 girls), with a mean age of seven years (3 to 12 ) by immobilisation with the elbow extended at Shanghai Children's Medical Center in China. We treated 51 consecutive children ( 44 boys and seven girls), with a mean age of eight years (3 to 12) by immobilisation with the elbow flexed at Schneider Children's Medical Center in Israel (Table I).
In the extended-elbow group, 36 fractures were on the right side and 24 on the left; $25 \%$ involved the radius, $8 \%$ the ulna, and $67 \%$ both. Of the fractures, three $(5 \%)$ were located in the proximal third of the bone, $25(41 \%)$ in the midshaft (mean age 5.5 years (3 to 12$)$ ), and $32(54 \%)$ at the distal end (mean age 8.8 years (3 to 12$))$. In the flexed-elbow group, 29 fractures were on the right side and 22 on the left; $11(22 \%)$ involved the radius, one $(2 \%)$ the ulna, and $39(76 \%)$ both. There was one $(2 \%)$ in the proximal third of the bone, 27 $(53 \%)$ in the midshaft (mean age 7.4 years $(3$ to 12$)$ ), and $23(45 \%)$ at the distal end (mean age 8.7 years ( 3 to 12 ) (Table I)).

In the extended-elbow group, there were 21 $(35 \%)$ greenstick fractures with an angulation of more than $15^{\circ}$ and $39(65 \%)$ complete fractures with displacement. In the flexed-elbow group, there were 20 (39\%) greenstick fractures with an angulation of more than $15^{\circ}$ and $31(61 \%)$ complete fractures with displacement (Table I).

Management. Diagnostic anteroposterior (AP) and lateral radiographs were taken in all patients. In both groups, reduction was performed according to previously published methods. 3,5

In the extended-elbow group, reduction was performed in the emergency room in 43 patients under sedation. Reduction was confirmed radiographically, and if the findings were not satisfactory, the procedure repeated 
Table I. Details and management of the two groups

\begin{tabular}{|c|c|c|c|}
\hline & $\begin{array}{l}\text { Extended-elbow } \\
(\mathrm{n}=60)\end{array}$ & $\begin{array}{l}\text { Flexed-elbow } \\
(n=51)\end{array}$ & $p$ value \\
\hline Age in yrs (range) & 7 (3 to 12$)$ & 8 (3 to 12$)$ & 0.115 \\
\hline \multicolumn{4}{|l|}{ Gender } \\
\hline Boys (\%) & $44(73)$ & $44(86)$ & 0.1099 \\
\hline Girls (\%) & $16(27)$ & 7 (14) & \\
\hline \multicolumn{4}{|l|}{ Side of fracture } \\
\hline Right (\%) & $36(60)$ & $29(57)$ & $0.8470 *$ \\
\hline Left (\%) & $24(40)$ & $22(43)$ & \\
\hline \multicolumn{4}{|l|}{ Bone involved } \\
\hline Radius (\%) & $15(25)$ & $11(22)$ & \\
\hline UIna (\%) & $5(8)$ & $1(2)$ & $0.275^{\dagger}$ \\
\hline Both (\%) & $40(67)$ & $39(76)$ & \\
\hline \multicolumn{4}{|l|}{ Site of fracture } \\
\hline Proximal end (\%) & $3(5)$ & $1(2)$ & \\
\hline Midshaft (\%) & $25(41)$ & $27(53)$ & $0.400^{\dagger}$ \\
\hline Distal end (\%) & $32(54)$ & $23(45)$ & \\
\hline \multicolumn{4}{|l|}{ Type of fracture } \\
\hline Greenstick (\%) & $21(35)$ & $20(39)$ & $0.6958 *$ \\
\hline Complete (\%) & $39(65)$ & $31(61)$ & \\
\hline
\end{tabular}

* Fisher's exact test

† chi-squared test

under general anaesthesia with the aid of an image intensifier. We treated 17 children in the extended-elbow group from the start under general anaesthesia.

In 22 children in the flexed-elbow group, reduction was performed in the emergency room under local anaesthesia using an intrahaematoma injection of lidocaine $1 \%$ and confirmed by radiographic examination. If the reduction was unsatisfactory, it was repeated under general anaesthesia. The remaining 29 children were treated from the start under general anaesthesia with the aid of an image intensifier.

An above-elbow plaster cast was applied over cast padding, with the elbow in extension or flexion and with the forearm in the most stable position of rotation. AP and lateral radiographs were taken one and two weeks after reduction. If there was no further displacement, the cast was removed at four to six weeks, and a radiograph taken to confirm healing. Clinical examination was repeated three months after removal of the cast to assess movement of the elbow and forearm.

Self-help and writing ability were assessed during immobilisation to compare the extended and flexed positions of the elbow. After two weeks of cast immobilisation, the children were asked to eat with a spoon or chopsticks, take off a shirt, and write a three-word sentence unaided. Cast fit was assessed by examination of the radiograph after reduction.

The data were recorded on a Microsoft Excel file (Microsoft Corp, Redmond, Washington) and submitted for independent statistical analysis with the Fisher's exact test and chi-squared test.

\section{Results}

There were no significant differences between the groups in mean age $(p=0.115)$, gender distribution $(p=0.1099)$, involved hand $(\mathrm{p}=0.8470)$, and involved bone $(\mathrm{p}=0.275)$ (Table I). In the extended-elbow group, $21(35 \%)$ of the children presented with greenstick fractures $>15^{\circ}$ of angulation and $39(65 \%)$ with complete, displaced fractures. The corresponding incidence in the flexed-elbow group was $20(39 \%)$ and $31(61 \%)$; neither of these differences was statistically significant $(\mathrm{p}=0.6958)$. The distribution of the site of fracture was also similar in the two groups $(\mathrm{p}=$ 0.400 ) (Table I).

No redisplacement occurred in the extended-elbow group, and all healed uneventfully.

During the first two weeks after reduction, nine patients $(17.6 \%)$ in the flexed-elbow group presented with redisplacement of the fracture, defined as an angulation of $>15^{\circ}$ on the follow-up radiograph. Three had redisplacement in the midshaft (age 5, 6, 12 years) and six at the distal end (mean age 8.3 years (6 to 12)). Six of these patients had complete fractures of the radius and ulna (three midshaft, three distal end), two had complete fractures of the radius (distal), and one had a greenstick fracture of the radius and ulna (distal). All the patients whose fractures redisplaced showed minimal displacement with or without angulation of up to $5^{\circ}$ on the immediate radiograph after reduction. Treatment consisted of repeat reduction under general anaesthesia. The mean time between fracture and remanipulation was 11 days. All fractures were still mobile at this stage. In all cases, healing with good alignment was obtained.

There was no cast slippage in either group. Radiographs of the redisplaced fractures showed adequate cast fit.

In the first three months after removal of the plaster cast a full range of elbow movement and forearm rotation was regained in both groups. All children required help with activities of daily living during cast immobilisation, regardless of whether the elbow was extended or flexed.

\section{Discussion}

In this study immobilisation of forearm fractures with the elbow extended produced better results than with the elbow flexed. Similar results were published in three previous studies of forearm fractures treated by immobilisation with the elbow extended; ${ }^{4-6}$ redisplacement was noted in only one patient. By contrast, Waters ${ }^{3}$ reported a $30 \%$ redisplacement rate after reduction and immobilisation of distal forearm fractures with the elbow flexed.

Several factors may contribute to the stability of the fracture after reduction such as age, bone involved, the site of the fracture and the initial angulation and displacement. All of these were similar in the two groups in our study. The role of age remains controversial. ${ }^{2,3}$ Waters ${ }^{3}$ claimed that the risk of loss of reduction increased with age, whereas Haddad and Williams ${ }^{2}$ found no discernible relationship between redisplacement and age. In this study, the mean age of those with redisplacement of the fracture was the same as for the whole group with distal forearm fractures, whether immobilised with the elbow extended or flexed. 
Furthermore, two of the three children whose midshaft fractures redisplaced were aged five and six years, which is close to the mean age of the children who presented with a midshaft fracture in the extended-elbow group, in which no redisplacement occurred. These findings suggest that age difference between the groups did not contribute to the different rates of redisplacement.

Boyer et $\mathrm{al}^{1}$ claimed that in children with distal-third forearm fractures, the position of immobilisation did not significantly affect the residual angulation at the time of union. In this study, the most stable position of reduction of the forearm (neutral, supine, prone) was determined by the attending resident. Although application of the cast may lead to redisplacement, in both our centres, fracture reduction and plaster application were performed by experienced residents. Radiographs of the redisplaced fracture showed that the casts had been satisfactorily applied.

A nonanatomical alignment on the initial post-reduction radiograph is also a high risk factor for redisplacement. ${ }^{2}$ In this series, the post-reduction radiographs showed only minimal residual displacement with $<5^{\circ}$ angulation in all children with redisplaced fractures. This degree of displacement is acceptable and warrants only weekly radiographic follow-up during the first few weeks, as was done in this study. ${ }^{7}$

Some authors claim that immobilisation of the elbow in extension may cause stiffness, whereas others have found no such association..$^{4-6}$ In the present study, all patients regained a full range of elbow movement within three months of removal of the cast.

The application of a plaster cast with the elbow extended is easy and, in our opinion provides better mechanical immobilisation of the fracture, thereby avoiding redisplacement.
Walker and Rang ${ }^{6}$ suggested that despite the advantages of maintaining unstable fractures in plaster casts with the elbow extended, this position is awkward for patients, and therefore advised the use of the flexion position. However, Shaer et $a{ }^{5}{ }^{5}$ found that children quickly adapt to the extended position. In this series, immobilisation with either an extended or flexed elbow interfered with daily activities and children in both groups required help with eating and dressing, and none could write a sentence easily.

We conclude that immobilisation of forearm fractures with the elbow extended is a safe and effective method for maintaining reduction.

\section{Supplementary Material}

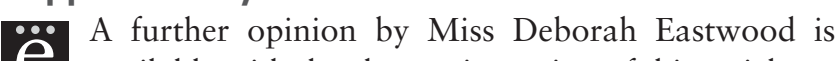
C available with the electronic version of this article on our website at www.jbjs.org.uk

No benefits in any form have been received or will be received from a commercial party related directly or indirectly to the subject of this article.

\section{References}

1. Boyer BA, Overton B, Schrader W, Riley P, Fleissner P. Position of immobilization for pediatric forearm fractures. J Pediatr Orthop 2002;22:185-7.

2. Haddad FS, Williams RL. Forearm fractures in children: avoiding redisplacement. Injury 1995;26:691-2.

3. Waters PM. Distal radius and ulna fractures. In: Beatty JH, Kasser JR, eds. Rockwood and Wilkins fractures in children. Fifth ed. Philadelphia: Lippincott, Williams \& Williams, 2001:413,415,427.

4. Gainor JW, Hardy JH 3rd. Forearm fractures treated in extension: immobilization of fractures of the proximal both bones of the forearm in children. J Trauma 1969;9: 167-71.

5. Shaer JA, Smith B, Turco VJ. Mid-third forearm fractures in children: an unorthodox treatment. Am J Orthop 1999;28:60-3.

6. Walker JL, Rang M. Forearm fractures in children: cast treatment with the elbow extended. J Bone Joint Surg [Br] 1991;73-B:299-301.

7. Noonan KJ, Price CT. Forearm and distal radius fractures in children. J Am Acad Orthop Surg 1998;6:146-56. 